\title{
Key Factors Affecting the Preparation and Properties of Reactive Powder Concrete
}

\author{
Yushuai Wang ${ }^{1, a}$, Cuixiang Xin ${ }^{2, b}$ and Zhiyong Liu ${ }^{3, c}$ \\ ${ }^{1,2,3}$ School of Civil Engineering,Yantai Univ, Yantai 264005, China \\ a2279049034@qq.com, bwjjxcx@163.com, 'Izy1698@163.com
}

\begin{abstract}
Keywords: RPC; mix proportion;fluidity; strength; durability
Abstract: Several key factors such as water binder ratio, dosage of water reducing agent, sand cement ratio and volume fraction of steel fiber affecting preparation and properties of reactive powder concrete are analyzed. The test results show that water binder ratio is one of the most important factors affecting the performance of RPC. Addition of superplasticizer helps RPC achieve good fluidity with a lower water binder ratio.Adding steel fiber can greatly improve the mechanical properties of RPC,but when the steel fiber content exceeds $2 \%$ the workability is getting worse. The compressive strength decline accordingly. Appropriate curing regimes contribute to higher early strength and appropriate late strength growth of RPC specimens. The compressive and flexural strength of the optimized mixture proportion of RPC specimens can reach $166.8 \mathrm{MPa}$ and $32.23 \mathrm{MPa}$ respectively. The chloride ion penetration test shows the prepared RPC has excellent durability.
\end{abstract}

\section{Introduction}

Reactive powder concrete (RPC) is a kind of super strength, high toughness, high durability, good volume stability of cement-based composite materials [1].It has the advantages of high material homogeneity, less internal defects, good particle size distribution and improvement of microstructure. RPC has a broad application prospect in the bridge, nuclear power, ocean, oil, military facilities and other industrial and civil construction projects with its superior performance [2]. Many countries have already applied it into practical projects and achieved good social and economic benefits. In China, Hunan province, Fang Zhi ,Huang Zhenyu et.al. successfully applied RPC to the construction of precast bridges in 2016. In order to better understand the main factors that affect the main physical mechanical properties of RPC, improve performance and reduce cost, so as to more RPC products were applied into practical engineering in the future. The main factors affecting the physical and mechanical properties of RPC are studied experimentally based on local raw materials in this paper.

\section{Materials, Mix Proportion and Preparation}

Materials.Portland cement P.I.52.5, silica fume with density of $2.214 \mathrm{~g} / \mathrm{cm}^{3}$ and average particle size of $0.31 \mu \mathrm{m}$, fly ash with density of $2.21 \mathrm{~g} / \mathrm{cm}^{3}$ and average particle size of $0.6 \mu \mathrm{m}$, polycarboxylate superplasticizer with $26 \%$ water reduction, quartz sand with continuous grading between $150 \mu \mathrm{m}$ to $600 \mu \mathrm{m}$, quartz powder with average size of $45 \mu \mathrm{m}$, and copper plated steel fiber with diameter $0.17 \mathrm{~mm}$ and length $13 \mathrm{~mm}$ were used in this experiments.

Experimental design and mix proportion.Based on the standard(GB/T31387-2015), the experimental design and concrete mix proportion were shown in Table 1. 
Table 1 Mix proportion of RPC

\begin{tabular}{ccccccccc}
\hline $\begin{array}{c}\text { Column } \\
\text { number }\end{array}$ & W/B & Cement & SF/C & FA/C & $\begin{array}{c}\text { Steel fiber } \\
\text { (volume/\%) }\end{array}$ & $\begin{array}{c}\text { Quartz } \\
\text { powder/ } \\
\text { cement }\end{array}$ & $\begin{array}{c}\text { Quartz } \\
\text { sand/ } \\
\text { cement }\end{array}$ & $\begin{array}{c}\text { Water } \\
\text { reducer }\end{array}$ \\
\hline A1 & 0.18 & 1 & 0.25 & 0.2 & 2 & 0.20 & 1.1 & 2.0 \\
A2 & 0.18 & 1 & 0.25 & 0.2 & 2 & 0.20 & 1.4 & 2.0 \\
A3 & 0.18 & 1 & 0.25 & 0.2 & 2 & 0.20 & 1.7 & 2.0 \\
A4 & 0.18 & 1 & 0.25 & 0.2 & 2 & 0.20 & 2.0 & 2.0 \\
B1 & 0.18 & 1 & 0.25 & 0.2 & 0 & 0.20 & 1.4 & 2.0 \\
B2 & 0.18 & 1 & 0.25 & 0.2 & 1 & 0.20 & 1.4 & 2.0 \\
B3 & 0.18 & 1 & 0.25 & 0.2 & 2 & 0.20 & 1.4 & 2.0 \\
B4 & 0.18 & 1 & 0.25 & 0.2 & 3 & 0.20 & 1.4 & 2.0 \\
C1 & 0.16 & 1 & 0.25 & 0.2 & 2 & 0.20 & 1.4 & 2.0 \\
C2 & 0.18 & 1 & 0.25 & 0.2 & 2 & 0.20 & 1.4 & 2.0 \\
C3 & 0.20 & 1 & 0.25 & 0.2 & 2 & 0.20 & 1.4 & 2.0 \\
C4 & 0.22 & 1 & 0.25 & 0.2 & 2 & 0.20 & 1.4 & 2.0 \\
D1 & 0.18 & 1 & 0.25 & 0.2 & 2 & 0.20 & 1.4 & 2.0 \\
D2 & 0.18 & 1 & 0.25 & 0.2 & 2 & 0.20 & 1.4 & 2.5 \\
D3 & 0.18 & 1 & 0.25 & 0.2 & 2 & 0.20 & 1.4 & 3.0 \\
D4 & 0.18 & 1 & 0.25 & 0.2 & 2 & 0.20 & 1.4 & 3.5 \\
\hline
\end{tabular}

Specimens preparation and curing. The cement, fly ash, silica fume, quartz powder were poured into the mixer to stir 30s; then quartz sand, the water reducing agent and water were added into the mixer stirred $2 \mathrm{~min}$. Finally,the steel fiber was added to the mixer and stirred 3 to $5 \mathrm{~min}[3,4]$. The the specimen size for cubic compressive strength was $70.7 \mathrm{~mm} \times 70.7 \mathrm{~mm} \times 70.7 \mathrm{~mm}[5,6]$ and the flexural strength test of specimen size was $40 \mathrm{~mm}$ x $40 \mathrm{~mm}$ x $160 \mathrm{~mm}$ [7]. After standard curing of 24hours, the specimens were putted into the steam curing box. The temperature of the box was raised to $50 \pm 5^{\circ} \mathrm{C}$ with $12^{\circ} \mathrm{C} / \mathrm{h}$ heating rate maintaining for 3.5 hours. Then with the same heating rate, the temperature was raised to $85 \pm 5$ maintaining for 72 hours $[8,9]$. After the steam curing ,the specimens were cooled to room temperature in the curing box. Then the specimens were putted into the standard curing room and maintained to $7 \mathrm{~d}$ or $28 \mathrm{~d}$.

Test methods. The fluidity tests was carried out according to GB/T2419-2005[10]. The mechanical properties were done based on GB/T31387 - 2015 and JGJ/T70-2009. Test of chloride migration coefficient was carried out according to the GB/T50082-2009.

\section{Test Results and Analysis}

Effect of sand to cement ratio on the performance of RPC.It can be seen from table 2 that with the increasing of the sand to cement ratio, the flexural strength of RPC decreases and the compressive strength increase firstly and then decrease. When the sand to cement ratio is 1.40 , the compressive strength and the fluidity is relatively good; Generally, the difference between strength of 7days and 28 days are not obvious. It is indicated that the steam curing method in the earlier stage largely stimulated the strength of RPC.

Table 2 The effect of sand to cement ratio on behavior of RPC

\begin{tabular}{ccccccc}
\hline \multirow{2}{*}{ Number } & Quartz sand & \multirow{2}{*}{$\begin{array}{c}\text { Fluidity } \\
\text { / Cement }\end{array}$} & $(\mathrm{mm})$ & \multicolumn{2}{c}{ Compressive } & \multicolumn{2}{c}{ Flexural } \\
& & & $7 \mathrm{~d}$ & $28 \mathrm{~d}$ & $7 \mathrm{~d}$ & $28 \mathrm{~d}$ \\
\hline $\mathrm{A} 1$ & 1.1 & 140 & 151.3 & 146.5 & 31.26 & 31.92 \\
$\mathrm{~A} 2$ & 1.4 & 120 & 152.0 & 155.1 & 30.39 & 26.59 \\
$\mathrm{~A} 3$ & 1.7 & 110 & 146.6 & 149.1 & 28.03 & 28.04 \\
A4 & 2.0 & 105 & 142.4 & 147.6 & 26.78 & 26.83 \\
\hline
\end{tabular}


Effect of steel fiber content on the performance of RPC. It can be seen from table 3 that in a certain range, with the increasing of the volume fraction of steel fiber, the flexural strength of RPC increases. This is due to the incorporation of steel fiber can hold up the occurrence and development of RPC internal micro cracks and significantly increase the RPC strength, toughness and ductility. With the increasie of steel fiber content,the compressive strength of RPC increased significantly,but finally fell slightly.This is mainly due to the increase of steel fiber content,the cement paste used to wrap steel fibers also increases accordingly. At the same time, the overlap between steel fiber and steel fiber, which also leads to the increase of the internal friction force and makes the workability of the mixture become worse. As a result of excessive steel fiber makes the fluidity of RPC decreased, resulting in uneven mixing and vibration compaction, ultimately affect its performance.

The compressive strength of the $70.7 \mathrm{~mm} \times 70.7 \mathrm{~mm} \times 70.7 \mathrm{~mm}$ and $40 \mathrm{~mm} \times 40 \mathrm{~mm} \times 40 \mathrm{~mm}$ specimens were compared in table 3. From the table, we can see the compressive strength of small specimens is higher than that of large specimens, indicating that the size effect exists. But the effect of size effect is not obvious after adding steel fiber. As a quasi brittle material, the failure process of concrete is the process of crack generation, propagation and instability. After the fiber is added into RPC, the fiber can inhibit the development of the crack, which affects the size effect of the macro. Considering the strength and fluidity, the content of steel fiber should be about $2 \%$.

Table 3 The effect of steel fiber content on behavior of RPC

\begin{tabular}{ccccccccc}
\hline & $\begin{array}{c}\text { Steel fiber } \\
\text { Number }\end{array}$ & $\begin{array}{c}\text { Fluidity } \\
\text { content }\end{array}$ & $\begin{array}{c}\text { Compressive } \\
\text { strength(MPa) }\end{array}$ & \multicolumn{2}{c}{$\begin{array}{c}\text { Compressive } \\
\text { strength(MPa) }\end{array}$} & \multicolumn{2}{c}{$\begin{array}{c}\text { Flexural } \\
\text { strength(MPa) }\end{array}$} \\
& $(\%)$ & & $70 \times 70 \times 70)$ & $28 \mathrm{~d}$ & $7 \mathrm{~d}$ & $28 \mathrm{~d}$ & $7 \mathrm{~d}$ & $28 \mathrm{~d}$ \\
\hline B1 & 0 & 135 & 84.3 & 101.3 & 93.0 & 91.1 & 26.78 & 22.97 \\
B2 & 1 & 126 & 145.0 & 131.5 & 150.2 & 145.1 & 27.27 & 24.83 \\
B3 & 2 & 120 & 152.0 & 155.1 & 157.7 & 155.2 & 30.39 & 26.59 \\
B4 & 3 & 115 & 166.5 & 151.6 & 170.2 & 161.6 & 26.85 & 27.83 \\
\hline
\end{tabular}

Effect of water binder ratio on the performance of RPC.It can be seen from table 4 that with the increase of water binder ratio, the fluidity is increased,the flexural strength and compressive strength increase firstly and then decrease. This is because the water binder ratio is the basic factor affecting the strength of concrete.Under the requirement of RPC fluidity and vibration densification, the lower the water binder ratio, the higher the strength. This is because the lower the water binder ratio, the lower the porosity and micro cracks. The initial imperfection of the concrete is reduced and the strength is increased, But also need to consider the good construction performance. The water binder ratio of 0.16 has not been fully vibrating compaction, so that the intensity showed a trend of increasing firstly and then decreasing. Considering the influence of water binder ratio on the fluidity and strength of RPC, the best water binder ratio is 0.18 .

Table 4 The effect of water binder ratio on behavior of RPC

\begin{tabular}{ccccccc}
\hline Number & $\begin{array}{c}\text { water } \\
\text { binder }\end{array}$ & \multirow{2}{*}{$\begin{array}{c}\text { Fluidity } \\
\text { ratio }\end{array}$} & \multicolumn{2}{c}{$\begin{array}{c}\text { Compressive } \\
\text { strength(MPa) }\end{array}$} & \multicolumn{2}{c}{ Flexural } \\
& & $7 \mathrm{~d}$ & $28 \mathrm{~d}$ & $7 \mathrm{~d}$ & $28 \mathrm{~d}$ \\
\hline $\mathrm{C} 1$ & 0.16 & 115 & 153.6 & 146.8 & 22.31 & 22.09 \\
$\mathrm{C} 2$ & 0.18 & 120 & 152.0 & 155.1 & 30.39 & 26.59 \\
$\mathrm{C} 3$ & 0.20 & 140 & 143.3 & 148.1 & 36.68 & 29.46 \\
$\mathrm{C} 4$ & 0.22 & 160 & 125.5 & 125.5 & 32.53 & 20.93 \\
\hline
\end{tabular}

Effect of dosage of water reducing agent on the performance of RPC.From table 5, with the increase of dosage of water reducing agent, the RPC fluidity in turn increase but not obvious, the flexural strength and compressive strength firstly increase and then decrease. Increasing the amount of water reducing agent in a certain range, which can improve the fluidity of the mixture, but not the bigger the better. There bleeding and isolation situation when the dosage is 3.5\%.Too much dosage of 
water reducing agent will lower the performance of RPC and too little dosage of water reducing agent can not have enough water reducing effect. Considering the influence of water reducing agent content on the fluidity and strength .In this experiment the best dosage of water reducing agent is $2.5 \%$.

Table 5 The effect of dosage of water reducing agent on behavior of RPC

\begin{tabular}{|c|c|c|c|c|c|c|}
\hline \multirow[t]{2}{*}{ Number } & \multirow{2}{*}{$\begin{array}{l}\text { water } \\
\text { reducer }\end{array}$} & \multirow{2}{*}{$\begin{array}{l}\text { Fluidity } \\
\text { (mm) }\end{array}$} & \multicolumn{2}{|c|}{$\begin{array}{l}\text { Compressive } \\
\text { strength }(\mathrm{MPa})\end{array}$} & \multicolumn{2}{|c|}{$\begin{array}{c}\text { Flexural } \\
\text { strength(MPa) }\end{array}$} \\
\hline & & & $7 \mathrm{~d}$ & $28 \mathrm{~d}$ & $7 \mathrm{~d}$ & $28 \mathrm{~d}$ \\
\hline D1 & 2.0 & 120 & 152.0 & 155.1 & 30.39 & 26.59 \\
\hline D2 & 2.5 & 130 & 160.2 & 166.8 & 31.22 & 32.23 \\
\hline D3 & 3.0 & 135 & 128.0 & 137.0 & 29.92 & 31.30 \\
\hline D4 & 3.5 & bleeding & $*$ & $*$ & $*$ & $*$ \\
\hline
\end{tabular}

Chloride migration coefficient. The chloride migration coefficient of mixture D2 was studied.The results were listed in table7.

Table 6 Test data of chloride migration coefficient

\begin{tabular}{ccccccc}
\hline Number & $\mathrm{U}(\mathrm{V})$ & $\mathrm{T}\left({ }^{\circ} \mathrm{C}\right)$ & $\mathrm{L}(\mathrm{mm})$ & $\mathrm{X}_{\mathrm{d}}(\mathrm{mm})$ & $\mathrm{t}(\mathrm{h})$ & $\begin{array}{c}\text { chloride migration } \\
\text { coefficient }\left(10^{-12} \mathrm{~m}^{2} / \mathrm{s}\right)\end{array}$ \\
\hline 1 & 60 & 19.9 & 50.2 & 3.6 & 96 & 0.18 \\
2 & 60 & 20.3 & 49.5 & 4.1 & 96 & 0.21 \\
3 & 60 & 20.45 & 51.3 & 3.8 & 96 & 0.20 \\
\hline
\end{tabular}

The chloride migration coefficient of RPC was calculated according to:

$$
D_{R C M}=\frac{0.0239(273+T) L}{(U-2) \mathrm{t}}\left(X_{d}-0.0283 \sqrt{\frac{(273+T) L X_{d}}{U-2}}\right)
$$

Where $\mathrm{D}_{\mathrm{RCM}}$ is the chloride migration coefficient, $\mathrm{U}$ is the absolute value of the voltage applied, $\mathrm{T}$ is the average value of the initial temperature and the end temperature of the anode solution, $\mathrm{L}$ is the specimen thickness, $\mathrm{X}_{\mathrm{d}}$ is the average value of chloride penetration depth.

According to (CCES 01-2004) evaluation standard of chloride ion permeability of concrete. RPC has very good resistance to chloride ion penetration[11].

Possible Mechanism analysis of steel fiber reinforcement.The prepared RPC is a kind of composite material mixed with randomly distributed steel fibers in concrete. The interfacial bond between steel fiber and concrete controls the stress transmission of the fiber. When the concrete is subjected to external forces the stress can be transferred from the matrix to the fiber. After matrix cracking of the concrete, the fiber across the matrix bears the load and the interfacial bond also transfers the load back to the non cracked part of the matrix. At this point, the fiber is subjected to tensile stress across the crack and the concrete matrix is connected to remain as a whole. Thus greatly improving the toughness of concrete[12].

\section{Conclusions}

(1)Water binder ratio is one of the most important factors affecting the performance of RPC. Addition of superplasticizer helps achieve good fluidity, but excessive dosage of water reducing agent may lead to bleeding.

(2)Adding steel fiber can greatly improve the mechanical properties of RPC, but when the steel fiber content exceeds $2 \%$, the workability is getting worse. The compressive strength also has a certain decline. Proper amount of quartz sand can optimize the particle size distribution. Appropriate curing regimes contribute to higher early strength and appropriate late strength growth.

(3)By applying the optimized mix proportion (W/B 0.18, S/C1.4, volume fraction of steel fiber $2 \%$ and dosage of water reducer $2.5 \%$ ), the RPC compressive and flexural strength is $166.8 \mathrm{MPa}$, 
32.23 MPa respectively. The chloride migration coefficient reaches $0.20 \times 10^{-12} \mathrm{~m}^{2} / \mathrm{s}$. The prepared RPC has good mechanical property and excellent durability.

\section{Acknowledgments}

The authors are thankful for financial support from National Natural Science Foundation of China(51678520).

\section{References}

[1] Yanbin He:Experimental investigation on compounding technology and mechanical properties of reactive powder concrete [D], Fuzhou University,2003.

[2] Yanzhong Ju, Yong Yu and Dehong Wang. (in Chinese).China Concrete and Cement Products , 2015,(4):42-44.

[3]Yanzhong Ju,Guannan Zhou and Weiquan Zheng. (in Chinese).Journal of Northeast Dianli University, 2007,27(2):18-21.

[4]Yanzhong Ju, Dehong Wang and Mengxin Kang. (in Chinese).Journal of Basic Science and Engineering, 2013,21(2):299-306.

[5] Xueyuan Lv, Ying Wang,Chengjun Fu and Wenzhong Zheng. (in Chinese).Journal of Harbin Institute of Technology, 2014,46(10):1-9.

[6]Wenzhong Zheng and Xueyuan Lv. (in Chinese).Journal of Building Structures, 2015,36(10):44-58.

[7]Feng He,Zhengyu Huang. (in Chinese).China Concrete and Cement Products ,2000,(4):3-7.

[8]Yanzhong Ju,Dehong Wang,Qiuchen Li, Yuzhuo Jia and Qi Xiao. (in Chinese).Journal of Experimental Mechanics, 2011,26(3):254-259.

[9]Song Han, Yaqiu Tu, Mingzhe An and Ziruo Yu. (in Chinese).China Railway Science,2015,36(1):40-46

[10]Min Guo,Haiyan Li,Gang Liu and Xiaobing Li. (in Chinese).Sichuan Architecture,2014,34(6):232-237.

[11]Aihua Tang,Shangwei Wang, Lingzhi Jin and Shenghua Zhao. (in Chinese).Journal of Henan Polytechnic University(Natural Science),2015,34(1):116-123.

[12] Xiaosong Lin and Guolin Yang:High strength and super high strength of steel fiber concrete(Science Press, Beijing,2002). 